\title{
Study of the effect of natural factors on optimal capacity of renewable energy resources
}

Tatyana Tuguzova*, Melentiev Energy Systems Institute of Siberian Branch of the Russian Academy of Sciences, Irkutsk, Russia

\begin{abstract}
The paper briefly describes a methodological approach to determine the maximum effective capacity of a renewable energy source for an off-grid consumer, considering natural factors. The annual distribution of indicators of solar and wind energy resources in the northeastern regions of Russia is analyzed. The groups of the characteristic maximum of average monthly wind velocities and the areas of their manifestation are revealed. The results of studying the dependence of the optimal capacity of an off-grid wind power plant on the annual distribution of wind velocities at different wind potential values are presented. The installed capacity utilization factor of wind power plants is shown to depend on natural factors. The results of this study are applied as a basis for guidelines on the priority of using renewable energy sources subject to natural conditions. Keywords: Decentralized consumers, technique to determine optimal capacity, annual distribution, ratio between optimal capacity and consumer's maximum load.
\end{abstract}

\section{Introduction}

Insignificant scales of using renewable energy sources (RESs) in the Russian Federation are currently due to their high capital intensity, Hence, determination of the optimal capacity value for RESs to substantiate their use is a topical and significant task. Determining the optimal capacity and the effect of natural factors is more relevant for decentralized consumers. Electricity supply to such consumers is related to difficulties of fuel delivery and its high price rise due to their remoteness and underdeveloped transport infrastructure $[1,2]$. The bulk of such consumers are in the north-eastern regions of the country, therefore, the main attention is paid to these territories.

Note that due to the stochastic nature of renewable natural energy resources, the use of RESs for electricity supply to decentralized consumers is impossible without traditional energy sources. Both in Russia and abroad, in most cases, those are diesel power plants [3-5].

The previous studies have showed that under present-day price conditions, RESs are competitive only for off-grid consumers located in hard-to-reach areas, in order to replace part of the expensive fuel and to reduce subsidies for electric power generation [6-8].

In the addressed regions, the Republic of Sakha (Yakutia) is the leader in developing solar energy for decentralized consumers. There are currently 20 operating solar power plants (SPPs) with a capacity from $3 \mathrm{~kW}$ to $1 \mathrm{MW}$, including those located beyond the

\footnotetext{
* Corresponding author: sever@isem.irk.ru
} 
Polar Circle [9]. However, both SPPs and wind power plants (WPPs) operating in isolated areas are built without substantiation of their capacities [10,11].

Therewith, the use of RESs with the optimal capacity allows the maximum electric power to be produced at minimum capital investment.

\section{Methodology of studies}

This problem is solved by the methodological approach developed at the Laboratory of Energy Supply to Decentralized Consumers of Melentiev Energy Systems Institute of the Siberian Branch of the Russian Academy of Sciences (MESI SB RAS) to determine the maximum effective capacity of a renewable energy source for an off-grid consumer, considering natural factors. The approach is described in detail in [12].

The conditions for the competitiveness of RESs are determined at the first stage based on their aggregated indicators for the territory (region) on the assumption of equal costs on electricity supply. As a result, the obviously inefficient versions are excluded from further calculations and the amount of initial information is reduced. At the next stage, the monthly possible electric power generation by RESs with conversion of the potential indicators into the plant parameters is determined by the multifactor analysis and calculations. The capacity enumeration cycle with a corresponding calculation of the indicators is arranged. The units with different rated capacity are selected. The useful generation is determined by superposition of the possible generation with the annual electric power consumption schedule. Further, the ratio between the investment in RES and the cost of the substituted fuel at a supplementary energy source is calculated. The optimal capacity of RES corresponds to the version with the minimum ratio between these indicators. And the financial and cost efficiency of RES usage is calculated for this version. The calculations are applied to work out guidelines on renewable energy development in the territory, indicating specific locations of RESs. The methodological approach and the technique to determine optimal capacity are universal for all types of RESs.

The optimal capacity of RESs depends, to a greater extent, on two natural factors: the potential of renewable energy resources that is characterized by the installed capacity utilization factor, and the distribution pattern of its indicators throughout a year.

The higher the potential of natural energy resources, the lower the installed capacity of RESs is necessary to generate the same amount of electric power.

\section{Results of studies}

The main natural factor affecting the optimal capacity of RESs is the uneven annual distribution of renewable natural energy resources.

The analysis of the solar potential at more than 30 points in the addressed territory [1316] has revealed that its maximum value in summer months does not depend on the locality latitude. As an example, Fig. 1 provides comparative indicators of the solar radiation incidence on a horizontal surface from $46^{\circ} \mathrm{N}$ (Yuzhno-Sakhalinsk, Sakhalin Region) to $72^{\circ} \mathrm{N}$ (Taymylyr, Republic of Sakha (Yakutia)). The solar radiation incidence significantly increases in the north-south latitudinal direction in winters. The mainland or coastal location of the observation point has a greater effect in the summer months. At the coastal points (Fig. 1a), the maximum incidence is lower than in the mainland territory (Fig. 1b). This is explained by the greater number of cloudy days in the summer. Therefore, for the localities with close latitudes, the annual radiation incidence in the mainland is higher than that in coastal areas. 


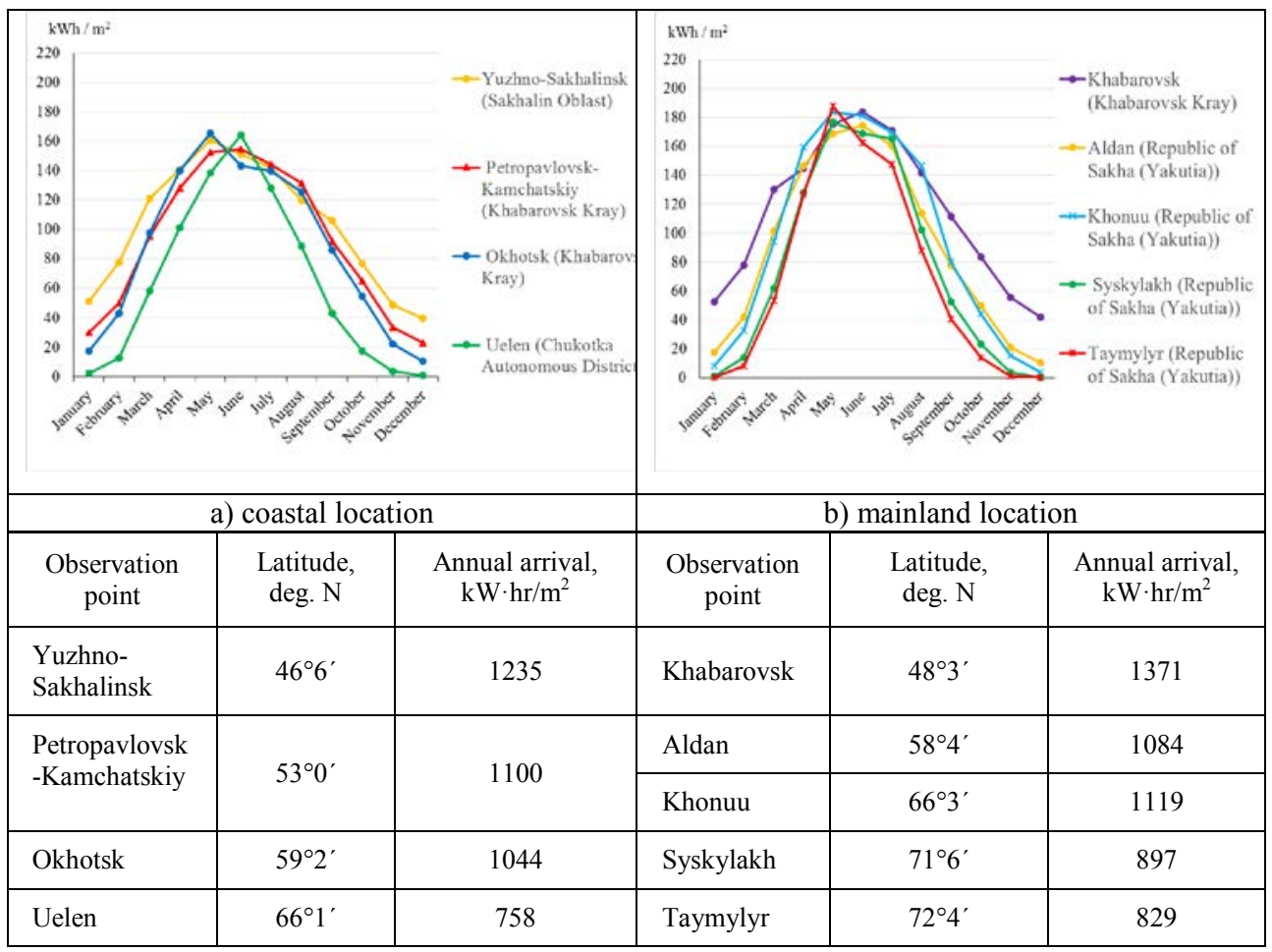

Fig. 1. Total solar radiation incidence on a horizontal surface

The pattern of the annual distribution of solar potential, regardless of the location, is the same and has a pronounced summer maximum. Therefore, this factor does not significantly affect the optimal capacity of solar power plants. Its value will decrease with an increase in the annual solar radiation incidence. Previous studies have showed that the cost of substituted diesel fuel has a greater impact on the efficiency of using solar power plants than the solar potential indicators [17].

The annual distribution of average wind velocities is more diverse. The analysis of the wind potential indicators for more than 50 points with weather observation stations revealed characteristic types of annual wind velocity distribution: with winter, summer, and spring-autumn maxima (Fig. 2).

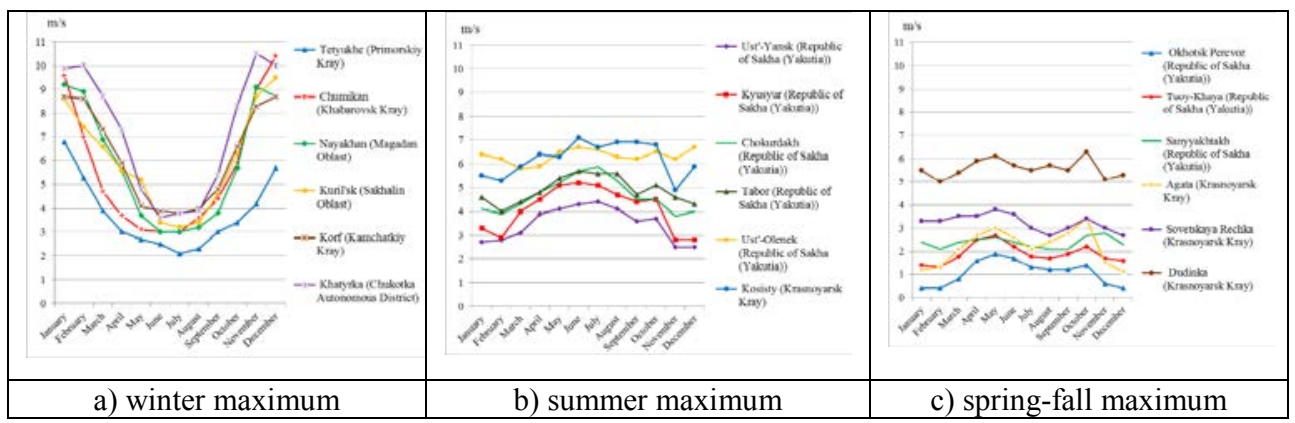

Fig. 2. Annual distribution of average monthly wind velocities 
The winter maximum is typical of the Pacific coast, the summer is characteristic of the Arctic Ocean coast, the spring-autumn maximum is more often observed on the mainland, where the wind velocities are much lower.

The developed technique was applied to calculate the optimal capacity for a wind power plant and its ratio to the maximum consumer's load for three types of the annual distribution, when the average annual wind velocities varied from 5 to $7 \mathrm{~m} / \mathrm{s}$. The results of studies show that the optimal capacity decreases with an increase in the average annual wind velocity. The minimum capacity value is typical of the winter maximum, the maximum value - of the spring-autumn maximum. At the same time, the impact of the average annual wind velocity distribution on the capacity value decreases with an increase in the average annual wind velocity (Fig. 3a).

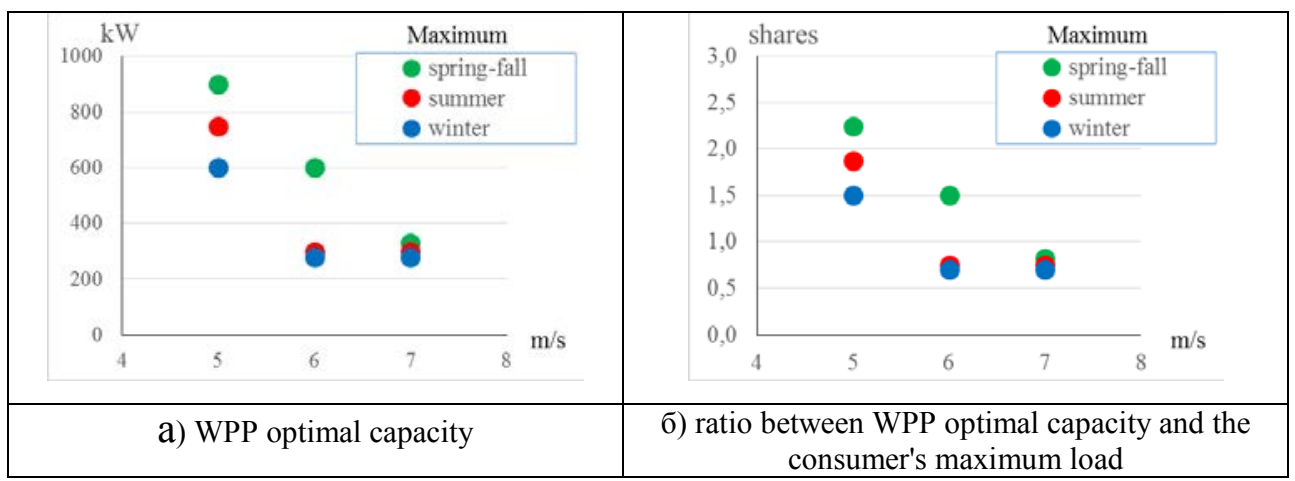

Fig. 3. Impact of the annual wind velocity distribution on the WPP optimal capacity, and the ratio between its optimal capacity and the consumer's maximum load

The ratio between the optimal capacity of a wind power plant and the consumer's load decreases with a wind potential increase. At small average annual wind velocities (about 5 $\mathrm{m} / \mathrm{s}$ ), the difference of this ratio is substantial: for the winter maximum, it is about 1.5 times, for the spring-autumn, it is about $2-2.5$ times. At $7 \mathrm{~m} / \mathrm{s}$ and higher, this ratio is less than 1 , regardless of the annual distribution type (Fig. 3b).

The installed capacity utilization factor of a wind power plant for all the wind potential values is higher at the winter maximum of wind velocity distribution (Fig. 4).

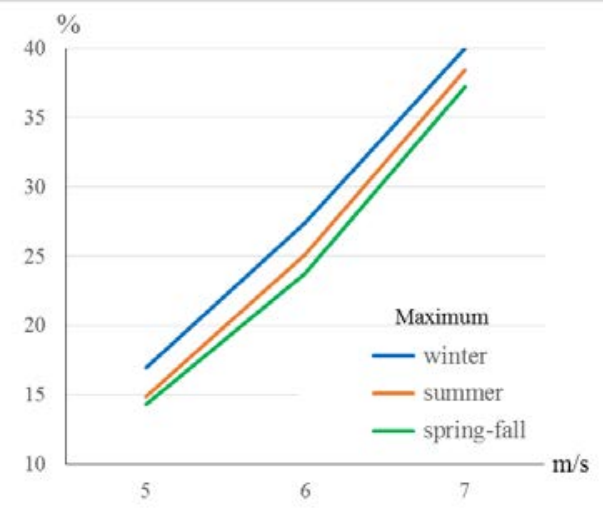

Fig. 4. Impact of the annual wind velocity distribution on the installed capacity utilization factor of a wind power plant 


\section{Conclusions}

The analysis of the conducted studies has showed that:

- dependence of the optimal capacity of a renewable energy source on the annual wind velocity and its ratio to the maximum consumer's load is hyperbolic at all types of the annual wind velocity distribution; the optimal capacity and the indicated ratio decrease with an increase in wind potential indicators;

- with the equal values of wind potential indicators, the highest value of this ratio is observed at the spring-autumn maximum of the average wind velocities, the lowest value is observed at the winter maximum;

- the most effective for the wind energy utilization is the annual velocity distribution at the winter maximum, where the installed capacity utilization factor is higher than that for other distribution types, because it is more consistent with the consumption schedule of decentralized settlements.

Based on this analysis, the following conclusions are drawn:

1. The Pacific coastal regions possess the best natural conditions for wind energy development.

2. Natural factors have a lower effect on the solar energy development than the ratio of price indicators.

3. For substantiation of the efficiency of using renewable energy sources, it is necessary to determine their optimal capacity, which will provide the investment minimization.

4. Based on the results of this study, it is possible to preliminary estimate the value of the optimal capacity of a renewable energy source as a function of the consumer's load and the indicators natural potential indicators.

\section{Acknowledgements}

The work was carried out within the framework of the scientific project III.17.6.1 of the program of fundamental research of the SB RAS, reg. No. AAAA-A17-117030310445-9.

\section{References}

1. B.G. Saneev, I.Yu. Ivanova, T.F. Tuguzova, A.K. Izhbuldin. Autonomous Energy Sources in the North of the Far East: Characteristics and Directions of Diversification. Spatial Economics, No. 1, pp. 101-116 (2018)

2. V.Kh.Berdin, A.O. Kokorin, G.M. Yulkin, M.A.Yulkin. Renewable energy sources in isolated settlements of the Russian Arctic. Moscow: World Wildlife Fund (WWF), 80 p. ISBN 978-5-906599-35-3 (2017)

3. B.G. Saneev, I.Yu. Ivanova, T.F.Tuguzova. The development of renewable energy in the east of Russia in the first half of the 21st century against the backdrop of allRussian trends. Energeticheskaya politika, № 3, pp. 66-73 (2016)

4. Diesel to Solar Transformation. Accelerating Achievement of SDG 7 on Sustainable Energy Assessing Untapped Solar Potential in Existing Off-grid Systems in the Arab Region. Egypt: Regional Center for Renewable Energy and Energy Efficiency, 48 p. (2016)

5. R. Hunter, G. Elliot. Wind/diesel Systems. Cambridge, UK: Cambridge University Press, 264 p. (1994) 
6. B.G. Saneev, I.Yu. Ivanova, T.F. Tuguzova. Renewable energy sources in regional energy programs in the east of Russia: prerequisites and rational scales. Energetik, No. 3, p. 6-9 (2014)

7. V.A. Minin, A.A. Rozhkova. Evaluation of the efficiency of joint operation of diesel capacity plants with wind capacity plants. Capacity plants, No. 6 (995), pp. 29-32 (2014)

8. PV Injection in Isolated diesel Grids. Feasibility Considerations / International Energy Agency. - 2007. - 12 p. [e-resource] - Access mode: http://www.ieapvps.org/index.php?id=368\&eID (Address date: 18 April 2018).

9. A.K. Koryakin. Experience in the exploitation of solar generation systems in the Far North conditions // Proceedings of the V international conference "Renewable energy in isolated systems of the Russian Far East. - Yakutsk. - 2017. [e-resource]. - Access mode:

http://www.eastrenewable.ru/upload/iblock/d5a/4_\%D0\%9A\%D0\%BE\%D1\%80\%D1 $\% 8 \mathrm{~F} \% \mathrm{D} 0 \% \mathrm{BA} \% \mathrm{D} 0 \% \mathrm{~B} 8 \% \mathrm{D} 0 \% \mathrm{BD}$. pdf. - (Address date: 10 April 2018).

10. M.A. Surkov, S.G. Obukhov, I.A. Plotnikov, L.P. Sumarokova, M.M. Popov, S.A. Baydali. Assessment of the advisability of using photovoltaic installations for capacity supply to remote consumers in the climatic conditions of the North of the Russian Federation / M.A. Surkov et al. Internet-journal "Naukovedenie", V. 8, No. 4, pp. 1-13 (2016). http: // naukovedenie.ru / PDF / 97TVN416.pdf.

11. P. Lundsager, E.I. Baring-Gould. Isolated Systems with Wind Capacity.Ackermann, T., ed. Wind Capacity in Capacity Systems, New York: John Wiley \& Sons, Ltd., pp. 299329 (2005)

12. I.Yu. Ivanova, T.F. Tuguzova, N.A.Khalgaeva. Determination of the optimal capacity of a renewable energy source for a consumer isolated from the energy system. Izvestiya RAN. Capacity engineering, №3, pp. 22-28 (2014)

13. Handbook on renewable energy resources of Russia and local fuels. / Indicators for territories. Moscow: "IAC Energia", 272 p. (2007)

14. Reference book on the climate of the USSR. Issue. 33. The Chukotka National District and the Magadan Region. Part 1. Solar radiation, radiation balance and sunshine. Leningrad: Gidrometeoizdat, 82 p. (1966)

15. Reference book on the climate of the USSR. Issue. 24. The Yakut ASSR. Part 1. Solar radiation, radiation balance and sunshine. Leningrad: Gidrometeoizdat, 96 p. (1967)

16. Reference book on the climate of the USSR. Issue. 25. The Amur Region, the Jewish Autonomous Region and the Khabarovsk Territory. Part 1. Solar radiation, radiation balance and sunshine. Leningrad: Gidrometeoizdat, 79 p. (1966)

17. I.Yu. Ivanova, T.F. Tuguzova, V.A. Shakirov, N.A. Khalgaeva. On the need to take into account various factors in justifying the use of heliopotential for capacity supply purposes using the example of Yakutia. Izvestiya RAN. Capacity engineering, №2, pp.41-54 (2018)

18. Reference book on the climate of the USSR. Issue. 24. The Yakut ASSR. Part 3. Wind. Leningrad: Gidrometeoizdat, 271 p. (1967)

19. Reference book on the climate of the USSR. Issue. 33. Magadan Region and Chukotka Autonomous District. Part 3. Wind. Leningrad: Gidrometeoizdat, 347 p. (1967)

20. Reference book on the climate of the USSR. Issue. 27. Kamchatka Region. Part 3. Wind. Leningrad: Gidrometeoizdat, 229 p. (1967)

21. Reference book on the climate of the USSR. Issue. 34. The Sakhalin Region. Part 3. Wind. Leningrad: Gidrometeoizdat, 248 p. (1967)

22. Reference book on the climate of the USSR. Iss. 21. The Krasnoyarsk Territory. Taimyr (Dolgano-Nenets National District). Evenki National District. Khakass 
Autonomous Region. The Tuva ASSR. Part 3. Wind. Leningrad: Gidrometeoizdat, 356 p. (1967)

23. Reference book on the climate of the USSR. Iss. 26. Primorye Territory. Part 3. Wind. Leningrad: Gidrometeoizdat, 192 p. (1967)

24. Reference book on the climate of the USSR. Iss. 25. Khabarovsk Territory. Amur region. Jewish Autonomous Region. Part 3. Wind. Leningrad: Gidrometeoizdat, 657 p. (1967) 